\title{
Embolisasi Preoperatif pada Operasi Dekompresi Tulang Belakang
}

\author{
Nathaniel Pali, ${ }^{1}$ Eko Prasetyo, ${ }^{2}$ Tommy Suharso, ${ }^{2}$ Richard Sumangkut, ${ }^{2}$ Billy Karundeng, \\ Harsali Lampus ${ }^{2}$
}

\author{
${ }^{1}$ Program Pendidikan Dokter Spesialis (PPDS) Ilmu Bedah Fakultas Kedokteran Universitas \\ Sam Ratulangi, Manado, Indonesia \\ ${ }^{2}$ Bagian Ilmu Bedah Fakultas Kedokteran Universitas Sam Ratulangi, Manado, Indonesia \\ Email: nathanielpali013@student.unsrat.ac.id
}

\begin{abstract}
Embolization is an effective way of controlling bleeding. This study was aimed to provide some information about preoperative spinal embolization, embolization materials, and complications. This was a literature review study using an online journal database and Google Scholar. The keywords used were Preoperative Spinal Embolization. The feasibility of the selected studies were case reports. The results showed that all studies used the same technique and approach to achieve different goals. The difference among them was the choice of embolan material. The complications that arose were few and could be managed. In conclusion, preoperative spinal embolization is the choice of therapy that give more benefit and safety.

Keywords: preoperative spinal embolization; spinal decompression surgery; embolan
\end{abstract}

\begin{abstract}
Abstrak: Embolisasi merupakan cara yang efektif dalam mengontrol perdarahan. Penelitian ini bertujuan memberikan informasi mengenai embolisasi tulang belakang, bahan embolan, dan komplikasi yang ditimbulkan. Jenis penelitian ialah suatu literature review menggunakan database jurnal online dan Google Scholar. Pencarian data menggunakan kata kunci Preoperative Spinal Embolization. Kelayakan penelitian yang dipilih bersifat case report. Hasil penelitian mendapatkan bahwa semua penelitian menggunakan teknik dan pendekatan yang sama untuk mencapai tujuan yang berbeda. Perbedaannya ialah dalam hal pemilihan bahan embolan. Komplikasi yang terjadi hanya sedikit dan dapat diatasi. Simpulan penelitian ini ialah preoperative spinal embolization merupakan terapi pilihan yang menguntungkan dan aman.
\end{abstract}

Kata kunci: embolisasi preoperatif; operasi dekompresi tulang belakang; embolan

\section{PENDAHULUAN}

Operasi dekompresi tulang belakang merupakan sebuah tindakan prosedur pembedahan untuk menghilangkan tekanan pada sumsum tulang belakang atau pada satu atau lebih akar saraf terkompresi yang melewati atau keluar dari tulang belakang. Dekompresi elemen saraf tulang belakang merupakan komponen kunci dalam mengobati radikulopati tulang belakang, mielopati, dan klaudikasio. Operasi dekompresi tersebut dapat berupa dekompresi pada serabut saraf. ${ }^{1}$

Terdapat banyak komplikasi yang dapat terjadi pada operasi dekompresi tulang belakang, salah satunya ialah perdarahan intraoperatif. Untuk mencegah perdarahan intraoperatif yang banyak maka diperlukan suatu tindakan embolisasi preoperatif. ${ }^{1}$ Embolisasi sendiri adalah prosedur bedah non-invasif atau bedah minimal yang dilakukan oleh ahli bedah vaskular. Pada prosedur ini dengan sengaja dilakukan penyuntikan emboli (materi penyumbat) ke dalam pembuluh darah terpilih untuk suatu tujuan medis tertentu. ${ }^{2}$

Embolisasi merupakan cara yang efektif untuk menangani kondisi perdarahan dan membatasi pasokan pendarahan untuk 
massa tumor. Embolisasi dapat dilakukan baik sebagai pengobatan definitif atau sebagai tambahan untuk manajemen bedah berikutnya. Aplikasi terapi emboli yang aman dan efektif membutuhkan ketrampilan tinggi dalam penggunaan kateter, pengenalan bahan emboli yang digunakan, dan pengetahuan tentang bahan khusus yang akan disuntikkan. ${ }^{3}$

Prosedur embolisasi pertama kali dilakukan pada tahun 1930-an untuk menyumbat fistula arteri karotis. Pada arteri karotis yang terekspos saat operasi, dapat digunakan otot, lemak dan fasia sebagai bahan emboli. Pada tahun 1968, bekuan darah otologus pertama kali digunakan sebagai bahan emboli untuk menyumbat malformasi arteri dan vena pada arteri spinal. Teknik ini kemudian digunakan pada perdarahan saluran cerna, perdarahan saluran genitourinari, dan perdarahan karena trauma misalnya pada fraktur pelvis. ${ }^{2}$

Pada tahun 1970, diperkenalkan tiga tipe baru materi embolik untuk penyumbatan intravaskular yang permanen, yaitu glue, coil (kumparan), dan polyvinyl alkohol foam. ${ }^{1}$ Penyumbatan pembuluh darah dapat dilakukan dengan penyumbatan mekanis langsung atau dengan kombinasi antara penyumbatan mekanis dan pembuatan trombus. ${ }^{2}$ Sejak dimulainya embolisasi kateter, telah terjadi kemajuan dalam penggunaan kateter embolisasi dan bahan yang digunakan, yang telah meningkatkan tindakan terapeutik dengan mengurangi kehilangan darah, waktu pembedahan, dan gejala sisa yang dihasilkan. ${ }^{4}$

Embolisasi preoperatif adalah prosedur yang memungkinkan kinerja, atau meningkatkan hasil, intervensi bedah berikutnya. Prosedur ini terus berkembang dan dilakukan saat ini. Pada awalnya hal ini merupakan prosedur preoperatif yang kemudian berkembang menjadi modalitas terapeutik yang berdiri sendiri. ${ }^{5}$ Salah satu contoh bahan embolan yang muncul untuk embolisasi ialah onyx ${ }^{\circledR}$ (Medtronic) yang memberikan hasil maksimal saat embolisasi. ${ }^{6}$ Tindakan embolisasi preoperatif pada operasi tulang belakang baik pada tumor, arteriovenous malformation (AVM), maupun sebelum operasi stabilisasi tulang belakang akibat trauma maupun degeneratif memberikan hasil yang cukup baik karena dapat mengurangi jumlah perdarahan intraoperasi. ${ }^{7-9}$ Hasil penelitian ini mendeskripsikan informasi tentang embolisasi preoperatif sebelum tindakan dekompresi tulang belakang maupun embolisasi yang bertujuan untuk mengecilkan ukuran tumor atau AVM. Terdapat banyak informasi yang dapat diperoleh dari berbagai kasus yang disajikan dalam penelitan ini, seperti keuntungan maupun kerugian embolisasi, komplikasi, bahan embolan, timing embolisasi, dan lainnya. ${ }^{10-16}$

Pada era modern dewasa ini, para tenaga kesehatan dituntut untuk memaksimalkan fasilitas yang ada dengan tujuan mengurangi morbiditas pasien, salah satunya yaitu memaksimalkan tindakan minimal invasif seperti embolisasi preoperatif yang dapat mengurangi perdarahan intraoperatif pada tulang belakang. Seiring berjalannya waktu, embolisasi preoperatif telah dikembangkan untuk mengurangi jumlah perdarahan pada operasi dekompresi tulang belakang.

Tulisan ini merupakan suatu literature review yang bertujuan untuk memberikan informasi tentang embolisasi tulang belakang baik teknik operasi hingga dampak yang dapat ditimbulkan akibat tindakan tersebut. Diharapkan pemahaman mengenai keuntungan dan kerugian embolisasi preoperatif pada operasi dekompresi tulang belakang dapat membantu dalam penanganan pasien secara umum maupun secara khusus bagi mereka yang membutuhkan tindakan embolisasi.

\section{METODE PENELITIAN}

Penelitian ini merupakan suatu literature review dengan menggunakan database dari perpustakan online dan jurnal online, serta Google Scholar. Kata kunci yang digunakan dalam pencarian ialah Preoperative Spinal Embolization. Pencarian kata kunci dilakukan dengan mencari padanan kata dari komponen pernyataan yang mungkin ditulis oleh penulis artikel. Artikel yang diperoleh disesuaikan dengan kriteria kelayakan penelitian, yaitu artikel case report atau serial case dalam bahasa 
Indonesia atau bahasa Inggris serta dapat diakses secara lengkap (fulltext).

\section{HASIL PENELITIAN}

Embolisasi merupakan suatu tindakan untuk menyumbat aliran darah yang dibuat untuk tujuan terapeutik, sebagai pengobatan hemostatik untuk perdarahan, atau sebagai pengobatan untuk memblokir pembuluh darah yang memasok makanan ke sel-sel tumor (feeding artery). ${ }^{7-9}$ Hal-hal yang dievaluasi dalam review ini yaitu teknik kateterisasi, pemilihan bahan embolan, hasil yang diperoleh, serta komplikasi pasca tindakan yang terjadi pada embolisasi tulang belakang sebelum operasi definitif.

Tabel 1 memperlihatkan tujuh jurnal yang dikaji dalam penelitian ini.

Tabel 1. Ringkasan kajian tujuh penelitian yang dianalisis

\begin{tabular}{|c|c|c|c|c|c|c|c|c|}
\hline No & Peneliti & Judul penelitan & $\begin{array}{l}\text { Metode } \\
\text { Penelitian }\end{array}$ & $\begin{array}{l}\text { Jumlah } \\
\text { Sampel }\end{array}$ & Alat dan Bahan & $\begin{array}{l}\text { Waktu } \\
\text { embolisasi }\end{array}$ & Hasil & Rekomendasi \\
\hline 1 & $\begin{array}{l}\text { Tuchmann } \\
\text { et al, } 2015^{10}\end{array}$ & $\begin{array}{l}\text { Novel applica- } \\
\text { tion of pre-ope- } \\
\text { rative vertebral } \\
\text { body emboliza- } \\
\text { tion to reduce } \\
\text { intra-operative } \\
\text { blood loss during } \\
\text { a three-column } \\
\text { spinal osteotomy } \\
\text { for non-oncologic } \\
\text { spinal deformity }\end{array}$ & Case report & 1 & $\begin{array}{l}\text { Mickelson } 5 \mathrm{Fr} \\
\text { Eselon } 10 \\
\text { Polyvinyl Alcohol } \\
(P V A) 250-500 \mu \\
\text { Gelfoam }\end{array}$ & $\begin{array}{l}1 \text { hari sebelum } \\
\text { operasi definitif }\end{array}$ & $\begin{array}{l}\text { Perdarahan } \\
\text { intraoperasi } \\
\text { definitif } \\
\text { berkurang }\end{array}$ & $\begin{array}{l}\text { Embolisasi tulang } \\
\text { belakang pre } \\
\text { operatif dapat } \\
\text { dilakukan untuk } \\
\text { mengurangi } \\
\text { perdarahan }\end{array}$ \\
\hline 2 & $\begin{array}{l}\text { Nakae et al, } \\
2017^{11}\end{array}$ & $\begin{array}{l}\text { Embolization of a } \\
\text { spinal dural } \\
\text { arteriovenous } \\
\text { fistula with } \\
\text { ethylene-vinyl } \\
\text { alcohol copoly- } \\
\text { mer (Onyx)using } \\
\text { a dual-lumen } \\
\text { microballoon } \\
\text { catheter and } \\
\text { buddy wire } \\
\text { technique }\end{array}$ & Case teport & 1 & $\begin{array}{l}5 \text { Fr catheter } \\
\text {-0,00165 inch inener } \\
\text { Ethylene-vinyl } \\
\text { alcohol copolymer } \\
0,35 \text { cc } \\
\text { Buddy wire } \\
\text { Dual lumen } \\
\text { microballon catheter }\end{array}$ & $\begin{array}{l}\text { Tidak } \\
\text { dilakukan } \\
\text { operasi definitif }\end{array}$ & $\begin{array}{l}\text { Tidak ada kom- } \\
\text { plikasi yang ter- } \\
\text { kait dengan } \\
\text { prosedur yang } \\
\text { terbukti }\end{array}$ & $\begin{array}{l}\text { Penggunaan } \\
\text { ethylene-vinyl } \\
\text { alcohol copolymer } \\
\text { dengan mengguna- } \\
\text { kan dual lumen } \\
\text { microballoon ca- } \\
\text { theter sangat efek- } \\
\text { tif }\end{array}$ \\
\hline 3 & $\begin{array}{l}\text { Tomura et } \\
\mathrm{al}, 2020^{12}\end{array}$ & $\begin{array}{l}\text { Stenting com- } \\
\text { bined with coil } \\
\text { embolization of a } \\
\text { dissecting } \\
\text { aneurysm after } \\
\text { traumatic } \\
\text { vertebral artery } \\
\text { injury }\end{array}$ & Case report & 1 & $\begin{array}{l}7 \text { fr sheath } \\
4 \text { fr sheath } \\
7 \text { fr guiding balloon } \\
\text { catheter } \\
\text { SL-10 STR } \\
\text { SL-10 pre-shaped } S \\
\text { Axium Prime } 3 D \\
\circledR(\text { Medtronic) } 3,5 \\
\text { mm } x 8 \mathrm{~cm} \\
\text { Neuroform Atlas }{ }^{\circledR} \\
\text { (Stryker) } 4,5 \times 30 \\
\text { mm }\end{array}$ & $\begin{array}{l}2 \text { minggu } \\
\text { sebelum } \\
\text { tindakan } \\
\text { definitif }\end{array}$ & $\begin{array}{l}\text { Embolisasi } \\
\text { sebelum } \\
\text { diseksi } \\
\text { aneurisma } \\
\text { memberikan } \\
\text { keuntungan }\end{array}$ & $\begin{array}{l}\text { Penggunaan } \\
\text { coiling untuk } \\
\text { embolisasi } \\
\text { preoperative } \\
\text { operasi tulang } \\
\text { belakang }\end{array}$ \\
\hline 4 & $\begin{array}{l}\text { Matsu- } \\
\text { moto et al, } \\
2021^{13}\end{array}$ & $\begin{array}{l}\text { Interventional } \\
\text { distal, emboli- } \\
\text { zation before } \\
\text { corrective cer- } \\
\text { vical spinal sur- } \\
\text { gery for post- } \\
\text { traumatic verte- } \\
\text { bral artery } \\
\text { occlusion: a case } \\
\text { report and } \\
\text { review of the } \\
\text { literature }\end{array}$ & Case report & 1 & $\begin{array}{l}5 \text { Fr guide catheter } \\
4 \text { FR JB2 catheter } \\
\text { Excelsior SL - } 10 \\
\text { microcatheter } \\
\text { CHIKAI 0,36 } \mathrm{mm} \\
\text { CHIKAI } 100,26 \mathrm{~mm} \\
\text { Hydrogel coil } \\
\text { buah) }\end{array}$ & $\begin{array}{l}3 \text { hari sebelum } \\
\text { operasi definitif }\end{array}$ & $\begin{array}{l}\text { Tidak ada kom- } \\
\text { plikasi prosedu- } \\
\text { ral yang diha- } \\
\text { dapi }\end{array}$ & $\begin{array}{l}\text { Embolisasi dengan } \\
\text { coil preoperatif da- } \\
\text { pat digunakan se- } \\
\text { bagai pilihan terapi } \\
\text { untuk mencegah } \\
\text { thromboembolic } \\
\text { stroke setelah ope- } \\
\text { rasi definitif }\end{array}$ \\
\hline
\end{tabular}




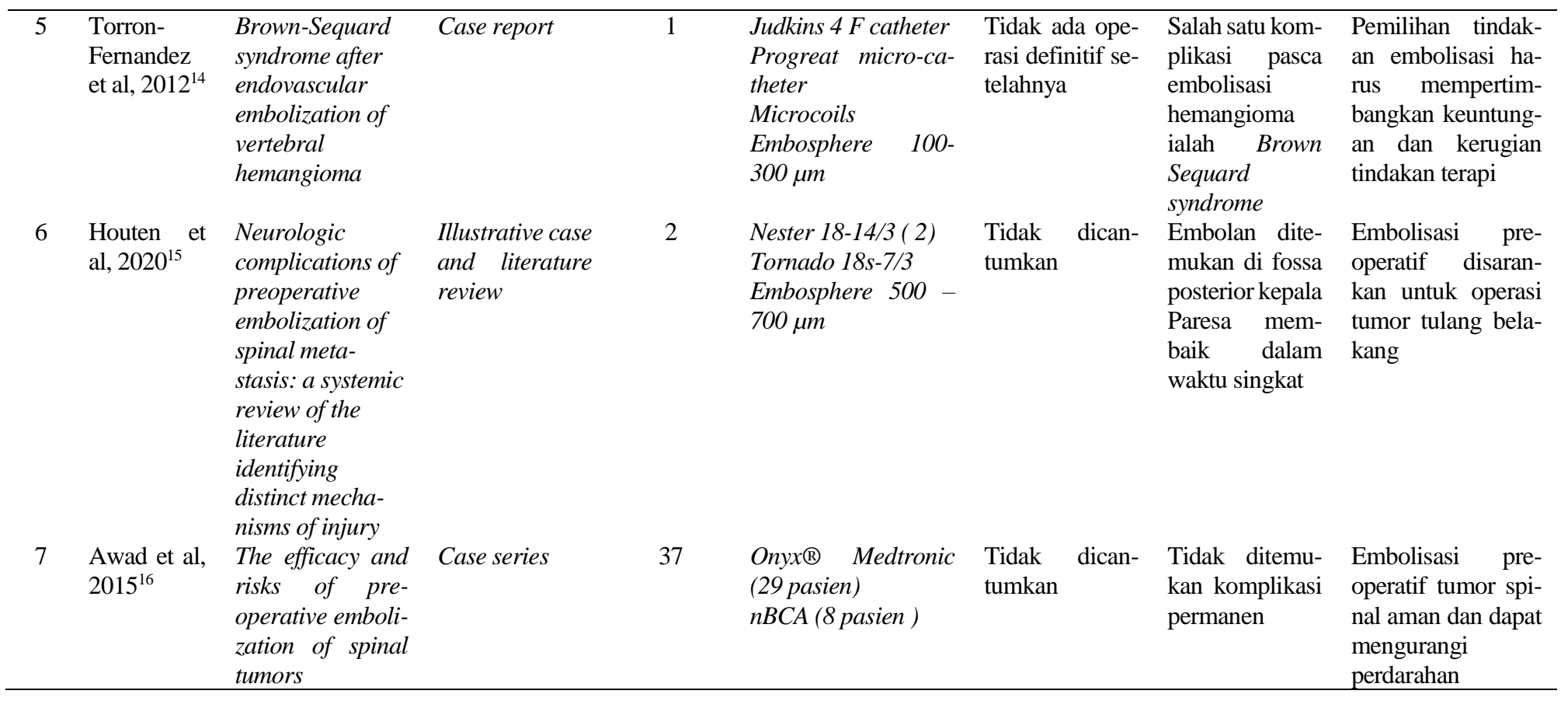

\section{BAHASAN}

Semua penelitian yang dikaji memberikan informasi tentang teknik dan pendekatan yang sama. ${ }^{10-16}$ Hal yang berbeda ialah bahan embolan yang digunakan. Coiling paling sering digunakan karena aman dan jarang terjadi perpindahan coiling ke tempat lain yang tidak diinginkan, disusul oleh onyx $®($ Medtronic), embosphere, dan PVA. Tuchmann et al ${ }^{10}$ menggunakan PVA tetapi pada penelitian tersebut PVA tidak dapat menyumbat pembuluh darah secara total yang akhirnya dikombinasikan dengan gel foam, sedangkan Tomura et al ${ }^{12}$ dan Matsumoto et al $^{13}$ menggunakan coiling pada penelitiannya dan tidak mendapatkan komplikasi pasca embolisasi. Pada penelitian Torron-Fernandez et al ${ }^{14}$ dan Houten et $\mathrm{al}^{15}$ digunakan materi embosphere dengan dosis yang bervariasi dan komplikasi yang didapatkan saat menggunakan embosphere yaitu Brown Sequard Syndrome serta salah satu embosphere pecah dan berpindah ke fossa posterior kepala yang mengakibatkan kelumpuhan sementara. Pada penggunaan bahan onyx ${ }^{\circledR}$ (Medtronic), coiling, maupun PVA tidak ditemukan komplikasi. ${ }^{10-16}$ Hal ini dapat memberikan informasi bahwa ketiga bahan tersebut termasuk bahan yang aman digunakan karena sangat jarang menimbulkan komplikasi dan jarang untuk gagal dalam tindakan embolisasi.

Timing embolisasi preoperatif menurut ketujuh penelitian yang dikaji bervariasi, antara sesaat sebelum operasi hingga dua minggu sebelum operasi. Hal ini memberikan informasi bahwa timing embolisasi preoperatif dikembalikan pada pengalaman operator yang melakukan embolisasi serta bahan material yang akan digunakan. Timing embolisasi yang lama sebelum tindakan definitif dikarenakan tujuan embolisasi menghentikan pasokan darah ke daerah tertentu untuk mematikan jaringan target seperti pada operasi tumor. ${ }^{10-16}$ Berdasarkan hal-hal yang telah dikemukakan maka tindakan embolisasi sangat direkomendasikan pada tujuan mengurangi pasokan darah ke tumor atau AVM (atau untuk downsizing) dengan timing operasi yang tepat ialah dua minggu sebelum tindakan definitif, sedangkan untuk mengurangi jumlah perdarahan pada operasi trauma timing embolisasi bervariasi dari sesaat sebelum tindakan hingga tiga hari sebelum tindakan; semakin cepat semakin baik karena dapat mengurangi length of stay (LOS) di rumah sakit tersebut.

Tuchmann et al $^{10}$ melakukan tidakan koreksi skoliosis dengan dua tahapan ope- 
rasi tulang belakang. Hari pertama operasi dilakukan bersamaan dengan embolisasi dan hari kedua operasi dilanjutkan hingga mencapai hasil yang diinginkan. Estimasi jumlah perdarahan pada kasus ini berkurang dibandingkan jumlah perdarahan yang terjadi sebelumnya (dianalisis oleh Tuchmann et al). Hal ini yang menjadi keunggulan utama dari embolisasi preoperatif, yakni mengurangi jumlah perdarahan.

Untuk teknik operasi embolisasi pada semua penelitian yang dikaji tidak dijelaskan secara rinci dikarenakan tidak ada variasi teknik yang dipakai dalam mencapai area embolisasi yang diinginkan. Besar kemungkinan tidak terdapat perbedaan teknik tindakan embolisasi pada kesemua penelitian ini. Semua tindakan embolisasi tersebut menggunakan akses via arteri femoralis dengan teknik Seldinger. Dengan panduan fluoroscopy, operator dapat mencapai akses ke area embolisasi yang diinginkan. ${ }^{10-16}$

Komplikasi yang muncul dari tindakan embolisasi preoperatif sendiri dapat berupa embolan pecah dan berpindah ke tempat lain, serta gangguan neurologik yang bersifat sementara dan kembali pulih setelah beberapa minggu pasca tindakan. Hampir semua penelitian yang dikaji tidak mendapatkan komplikasi neurologik yang permanen. Awad et al ${ }^{16}$ mendapatkan pada serial case adanya komplikasi pada saraf yang bersifat sementara dan membaik dalam jangka waktu singkat.

Berdasarkan hal-hal yang telah diuraikan dapat disimpulkan bahwa keuntungan embolisasi preoperatif pada operasi dekompresi tulang belakang yaitu dapat mengurangi jumlah perdarahan intraoperatif, mengurangi pasokan darah ke tumor atau AVM sebelum operasi definitif, dan mengurangi jumlah morbiditas yang muncul saat intraoperasi definitif. Kerugian embolisasi preoperatif yakni embolan yang digunakan dapat pecah dan berpindah ke tempat yang tidak diinginkan sehingga menimbulkan komplikasi neurologik yang bersifat sementara, tetapi komplikasi yang muncul dapat diatasi dengan terapi konservatif dan menghilang dalam waktu yang tidak lama.

\section{SIMPULAN}

Embolisasi preoperatif pada operasi dekompresi tulang belakang merupakan terapi pilihan yang menguntungkan dan aman digunakan. Pemilihan bahan embolan berperan penting dalam keberhasilan embolisasi. Pengalaman operator juga berperan penting dalam keberhasilan tindakan ini. Komplikasi neuorologik yang muncul hanya bersifat sementara dan kembali normal dalam waktu yang singkat.

\section{Konflik Kepentingan}

Penulis menyatakan tidak terdapat konflik kepentingan pada penelitian ini

\section{DAFTAR PUSTAKA}

1. Spinal decompression - Wikipedia [Internet]. 2021 [cited 2021 Aug 21]. Available from: https://en.wikipedia.org/wiki/ Spinal_decompression

2. Nimim PZ. Embolisasi dan bahan embolisasi [Internet]. Jakarta: Universitas Indonesia. [cited 2021 Aug1]. Available from: https://webcache.googleusercontent. com/search?q=cache:ZMz95PQzlnMJ: https://www.kankertht-kepalaleher. info/wp-content/uploads/2016/05/ Embolisasi-dan-bahan-embolisasi. $\mathrm{pdf}+\& \mathrm{~cd}=1 \& \mathrm{hl}=\mathrm{id} \& \mathrm{ct}=\mathrm{clnk} \& \mathrm{gl}=\mathrm{id}$

3. Herrera DA, Vargas SA, Dublin AB. Endovascular treatment of traumatic injuries of the vertebral artery. Am J Neuroradiol (AJNR). 2008;29(8):1585-9. Available from: http://www.ajnr.org/content/29/8/ 1585

4. Shah A, Choudhri O, Jung H, Li G. Preoperative endovascular embolization of meningiomas: Update on therapeutic options. Vol. 38, Neurosurg Focus. 2015;38:1-7.

5. Rilling WS, Chen GW. Preoperative embolization. Semin Intervent Radiol. 2004; 21(1):3-9.

Doi: $10.1055 / \mathrm{s}-2004-831400$.

6. Hauck EF, Welch BG, White JA, Purdy PD, Pride LG, Samson D. Preoperative embolization of cerebral arteriovenous malformations with onyx. Am J Neuroradiol (AJNR). 2009;30(3):492-5.

7. Embolization | meaning in the Cambridge English Dictionary [Internet]. [cited 2021 Aug 2]. Available from: https://dictionary.cambridge.org/diction ary/english/embolization 
8. Embolization | Definition of embolization by Merriam-Webster [Internet]. [cited 2021 Aug 2]. Available from: https: //www.merriam-webster.com/ dictionary/embolization

9. Embolization - Wikipedia [Internet]. [cited 2021 Aug 2]. Available from: https: //en.wikipedia.org/wiki/Embolization

10. Tuchman A, Mehta VA, MacK WJ, Acosta FL. Novel application of pre-operative vertebral body embolization to reduce intraoperative blood loss during a threecolumn spinal osteotomy for nononcologic spinal deformity. J Clin Neurosci. 2015;22(4):765-7.

11. Nakae R, Nagaishi M, Hyodo A, Suzuki K. Embolization of a spinal dural arteriovenous fistula with ethylene-vinyl alcohol copolymer (Onyx) using a duallumen microballoon catheter and buddy wire technique. Surgical Neurology International. 2017;8(1):166.

12. Tomura N, Kobayashi N, Matsunaga S, Shuto T, Masuo O. Stenting combined with coil embolization of a dissecting aneurysm after traumatic vertebral artery injury. J Neuroendovascular Ther. 2020;
14(2):56-61.

13. Matsumoto S, Tagawa M, Inoue A, Takeba J, Watanabe H, Kunieda T. Interventional distal embolization before corrective cervical spinal surgery for posttraumatic vertebral artery occlusion: a case report and review of the literature. $\mathbf{J}$ Neuroendovascular Ther. 2021. Doi: 10.5797/jnet.cr.2020-0204.

14. Fernandez-Torron R, Palma JA, Riverol M, Irimia $\mathrm{P}$, Martinez-Vila E. BrownSequard syndrome after endovascular embolization of vertebral hemangioma. Spinal Cord. 2012;50(8):636-7.

15. Houten JK, Swiggett SJ, Hadid B, Choueka DM, Kinon MD, Buciuc R, et al. Neurologic complications of preoperative embolization of spinal metastasis: a systemic review of the literature identifying distinct mechanisms of injury. World Neurosurgery. 2020;143:374-88.

16. Awad A_W, Almefty KK, Ducruet AF, Turner JD, Theodore N, McDougall CG, et al. The efficacy and risks of preoperative embolization of spinal tumor. $\mathbf{J}$ Neurointerv Surg. 2016;8(8):859-64. Doi: 10.1136/neurintsurg-2015-011833. 